\title{
Evolució que el professor de música experimenta en la forma de percebre i categoritzar l'ensenyament de la llengua estrangera durant una experiència d'Aprenentatge integrat de continguts i llengua (AICLE), en anglès
}

\author{
Anna Corredera Capdevila i Bruno J. Ruiz Lorenzo, Universitat Autònoma \\ de Barcelona, Espanya
}

\section{Introducció}

Un dels reptes dels països integradors de la Unió Europea és garantir que els ciutadans siguin capaços de funcionar còmodament en més d'una llengua estrangera. Partint d'aquesta consideració, el sistema educatiu del nostre país ha d’oferir l'entorn favorable per tal que els alumnes puguin aconseguir el nivell de competència adequada en llengua estrangera.

Els programes d'Aprenentatge integrat de continguts i llengua (AICLE ${ }^{1}$ ) estan obrint una porta a la millora de l'aprenentatge de la llengua meta ja que ofereixen als alumnes l'oportunitat d'utilitzar la llengua meta per apropiar-se de nous continguts curriculars. Nombrosos estudis avalen l'eficàcia d'aquests programes tant en l'aprenentatge de la llengua com del contingut, i confirmen que l'aprenentatge de continguts no queda afectat negativament per l'ús d'una llengua estrangera. No obstant, la percepció del professorat de contingut ${ }^{2}$ és sovint diferent. Un dels temes que no deixa de preocupar aquest professorat és la possible repercussió negativa que aquests programes poden tenir sobre l’aprenentatge de la matèria de la qual són responsables.

Considerant aquesta preocupació, el focus d’interès del present estudi ${ }^{3}$ és descriure l'evolució que experimenta un professor de contingut que s’ofereix a participar en una experiència innovadora d'ensenyament de la música en anglès. La rellevància d'aquesta investigació rau en el fet que és aquest professorat expert en la matèria el que se sent responsable de complir amb els requisits d'aprenentatge fixats pel currículum. Per aquesta raó comprendre la percepció i les expectatives que un especialista en una àrea determinada té sobre l'ensenyament de la matèria en llengua estrangera i veure l'evolució que aquestes expectatives experimenten al llarg del procés és clau per percebre l’èxit del programa i garantir-ne la continuïtat. 
Aquesta investigació és un estudi de cas en el que s’indaga en l'evolució que un professor de música experimenta en la forma de valorar la utilitat del programa AICLE i el procés d'apropiació de continguts meta per part dels alumnes que estan aprenent música en anglès en una aula de 3r d'ESO en un centre de Catalunya. Per tal de poder fer el seguiment d'aquesta evolució es van realitzar sis entrevistes el contingut de les quals es va transcriure i és l'objecte d'anàlisi d'aquest estudi qualitatiu. La interpretació de les dades evidencia l'evolució constructiva que experimenta el docent al llarg de l’experimentació i que el situa en un espai de reflexió sobre la seva pràctica docent.

\section{Marc teòric}

El professor de contingut que es brinda a participar en el projecte que es descriu en aquest article és la figura que desperta preguntes i reflexions. Per tal de conèixer els processos d'ensenyament-aprenentatge que tenen lloc a l'aula és rellevant indagar en el pensament del professor que està a l'aula (Ballesteros, Llobera, Cambra, Palou, Riera, Civera i Perera 2001). Nombrosos estudis s’han interessat pel pensament del professor, és a dir per les diferents idees, creences i sabers pràctics dels professors que afecten la planificació i l'acció a l'aula. Clark i Peterson (1986) van descriure detalladament la vida mental dels docents. Philip Jackson (citat en Clark i Peterson op. cit.) va realitzar un dels primers estudis en aquesta línia d’investigació i va destacar "la importancia de describir el pensamiento y la planificación de los maestros como medio de comprender mejor los procesos del aula”(p. 444). Existeix un ampli consens entre els investigadors d'aquest àmbit que creuen que hi ha una relació entre pensament i acció. El grup de recerca PLURAL (Plurilingüismes Escolars i Aprenentatge de Llengües) de la Universitat de Barcelona té una llarga trajectòria en estudis recents sobre el pensament del docent (Cambra 2000; Ballesteros et al. op. cit.). Tal i com Cambra (op. cit.) apunta en el seu estudi:

la recerca sobre el pensament del professor té com a beneficiaris no solament els investigadors $\mathrm{i}$ en últim terme l'àrea de coneixement de la didàctica de la llengua, sinó que també és profitosa per a tots els implicats en l'acte educatiu. És una bona font de reflexió [...] Els professors no són subjectes per ser estudiats des de fora, sinó que ells també construeixen significat durant el procés de 
recerca i reflexionen sobre la seva pròpia actuació i la dels seus alumnes. (p. 165)

De totes maneres, el pensament del professor no és estàtic ni immutable, sinó que evoluciona al llarg del temps segons acumula experiència i contrasta les seves idees amb la realitat que va experimentant. Tampoc evoluciona de forma aïllada, sinó conjuntament i a partir de les interaccions amb companys quan de forma institucionalitzada o informal es reflexiona conjuntament sobre el que succeeix a l'aula. Aquests espais de reflexió són necessaris per formar docents reflexius i millorar les pràctiques a l'aula. Aquesta idea prové del que Schön (1998) anomena una pràctica reflexiva.

La col·laboració entre professionals de l'educació i el treball amb la investigació en un context d'exploració d'aula produeix una gran riquesa de reflexió i coneixement que transformen la investigació en acció (Allwright i Bailey 1991).

La proposta d'ensenyament de llengua que es presenta en aquesta investigació integra a la vegada l'aprenentatge de la llengua meta i continguts curriculars d'una matèria. Es tracta del programa d’aprenentatge integrat de continguts i llengua (AICLE) o semiimmersió (SI). La integració de llengua i contingut és l’ingredient principal d'aquest programa, ja que la llengua s'ha d'utilitzar en un context real de significació per tal d'apropiar-se de nous continguts curriculars. Els treballs de Roquet i Escobar (2004), Escobar i Sánchez (2007 i 2009), Evnitskaya i Aceros (2008), Corredera (2008) i Escobar (2008a) són una mostra dels estudis que s’han realitzat sobre semiimmersió en llengua estrangera a Catalunya i que demostren l'efecte positiu que aquests programes tenen en l'aprenentatge de la llengua meta.

Una de les conclusions principals del projecte 2006ARIE 100011 és que la integració de llengua i contingut, que és la base d’aquests programes, implica el treball conjunt entre el professor de llengua i el professor de contingut per tal de garantir-ne l'èxit (Escobar 2008b). Els treballs de Pallarès i Petit (2008) i Horrillo-Godino (2008a i 2008b) demostren l'èxit del treball col-laboratiu entre dos experts a l'aula AICLE. Igualment l'estudi de Horrillo-Godino (2008b) mostra com es construeix l'espai de diàleg entre dos experts a l'aula AICLE. Anteriorment Do Coyle (2006) ja apuntava que building communities of practice is dependent on cooperation, collaboration and partnerships for learning. They involve content and language teachers working together $[. .$.$] and a genuine belief that for CLIL theory to guide practicioners, it$ 
must be 'owned' by the community, developed through classroom exploration and understood in situ- a theory of practice developed for practice through practice. (p. 22)

En el marc d'aquest estudi el disseny de les activitats d'aprenentatge està basat en una visió socioconstructivista i interaccionista de l'aprenentatge que es basa en el fet de no considerar la construcció del coneixement a l'escola com un procés de construcció individual de l’alumnat, sinó més aviat com un procés de construcció compartit entre professors i alumnes (Coll 2002). Així doncs, el professor adopta un rol de guia que acompanya l'estudiant en el procés d'aprenentatge i li proporciona la bastida necessària per tal que l'estudiant pugui construir el seu coneixement prenent un rol actiu en les activitats de l'aula. La perspectiva interaccionista sosté que la interacció entre els parlants és determinant en l'adquisició d’una llengua (Mondada i Pekarek 2004).

\section{El context de la investigació}

El centre ${ }^{4}$ on es va dur a terme aquesta experimentació és un centre concertat de Sant Adrià de Besòs. El centre està ubicat en un barri de classe treballadora on els recursos econòmics i culturals de les famílies són limitats.

Aquesta experimentació es va dur a terme en una classe de 3r d'ESO formada per 25 alumnes amb aptituds i nivells de competència diferents. L'experiència es va realitzar amb un grup de 3r d'ESO mentre que l'altre grup va continuar amb la programació habitual en català. Els responsables de realitzar el projecte van ser el professor de música (Llicenciat en música i competència en anglès Nivell C2 segons els nivells proposats pel Marc Comú Europeu de Referència per a les llengües) i la professora d'anglès que en el moment de la realització del projecte estava realitzant els estudis de Màster de Recerca de Didàctica de la Llengua i la Literatura a la Universitat Autònoma de Barcelona. El professor de música serà l'encarregat d'implementar la unitat didàctica durant les sessions de música i la professora d'anglès serà l'encarregada d'implementar-la durant les sessions d'anglès.

El projecte que aquests dos docents van realitzar consistia en dissenyar una unitat didàctica de música centrada en el tema del Romanticisme. Es van dissenyar diferents activitats per abordar els continguts d'aquest tema que es van realitzar durant 
tres setmanes en les sessions de música (una hora setmanal) i les sessions d'anglès (tres hores setmanals). El conjunt d'hores dedicades a la unitat va sumar un total de 9 sessions en les que es garantia la màxima exposició a la llengua meta i el temps suficient per apropiar-se dels continguts meta tot prenent un rol actiu en les activitats d'aprenentatge. Cal recalcar el fet que tant el disseny com l'execució de la unitat didàctica van ser fruit del treball conjunt entre el professor de música i la professora d’anglès.

\section{Objectiu i preguntes}

L’objectiu d'aquesta investigació és reconstruir a partir de successives entrevistes de treball amb el professor el procés d'evolució en la forma en què aquest professor de contingut percep i categoritza els esdeveniments que succeeixen a l'aula AICLE en relació a l'apropiació de continguts meta per part dels estudiants.

Les preguntes que guien aquesta investigació són: com es desenvolupa el procés de planificació i implementació de la unitat didàctica? i ¿com evoluciona la percepció del professor de contingut sobre l'ensenyament de la seva matèria d'especialització en llengua estrangera des del principi fins al final del projecte?

\section{Marc metodològic}

L'anàlisi d'aquest estudi de cas es realitza des d'una perspectiva qualitativa i interpretativa. La comprensió d'aquest procés d'evolució no és la finalitat última de l'estudi, ja que també s’orienta a la transformació de la pràctica docent, seguint l’enfocament de la investigació-acció que proposen Cohen i Manion (1985).

L’anàlisi de les dades referents al pensament del professor es realitza a través d'una anàlisi del contingut. L'anàlisi del contingut que es realitza en aquest estudi segueix la línia de l’anàlisi convencional proposat per Hsieh i Shannon (2005). Segons aquests autors, l'anàlisi del contingut comença amb una lectura de les dades per aconseguir immersió en el contingut i obtenir el sentit general. Després d'aquest estadi l'investigador va marcant els temes que es fan rellevants al llarg de les dades i aquest procés segueix fins a marcar les categories que es pretén analitzar. 
La recollida de les dades va ser complexa ja que es pretenia recollir el màxim de dades possibles per poder comprendre millor el procés que es volia descriure. Les dades recollides es poden classificar en dades principals i dades complementàries:

\begin{tabular}{|l|ll|}
\hline \multicolumn{2}{|c|}{ Dades principals } & \multicolumn{1}{|c|}{ Dades complementàries } \\
\hline - $\quad \begin{array}{l}\text { entrevistes al professor de música } \\
\text { notes de camp de la investigadora } \\
\text { (anotacions de la investigadora durant la } \\
\text { confecció de la unitat didàctica) }\end{array}$ & - & $\begin{array}{l}\text { diaris dels alumnes (anotacions dels } \\
\text { alumnes després de cada sessió de música }\end{array}$ \\
& $\begin{array}{l}\text { per recollir les seves impressions) } \\
\text { notes de camp del professor de música } \\
\text { (anotacions del docent quan marca els } \\
\text { objectius que vol aconseguir al final de la } \\
\text { unitat didàctica) } \\
\text { diari de l'observador (impressions de la } \\
\text { investigadora durant les classes de música) }\end{array}$ \\
\hline
\end{tabular}

Taula 1. Dades de l'estudi

De les dades principals, les entrevistes al professor de música seran l’objecte prioritari d'anàlisi en aquest estudi i les notes de camp de la investigadora serviran per reconstruir la memòria del procés de disseny de la unitat didàctica. Les dades complementàries permeten formular una interpretació contrastada dels temes que seran objecte d'estudi al llarg de les entrevistes ja que la referència a aquestes dades apareix en les entrevistes.

Es va considerar que l'entrevista era un instrument adequat que permetia recollir dades de tipus discursiu sobre l'evolució en la forma de pensar del docent i aquestes dades eren susceptibles de ser analitzades a través d'una anàlisi del contingut. El tipus d'entrevista respon a l'entrevista no-estructurada i amb preguntes obertes (Silverman 1993). Burgess (1982) considera que l'entrevista no-estructurada és una tècnica que proporciona més profunditat en les dades que qualsevol altra tècnica d’investigació ja que "unstructured interviews involve the sort of conversation that is developed through a sustained relationship between the informant and the researcher. Such interviews can yeld a variety of rich material”(p.109). Partint d'aquestes consideracions, es van realitzar sis entrevistes al professor de música durant els temps següents:

-entrevista 1: es va realitzar després que el docent acceptés la proposta i abans de planificar la unitat didàctica. En aquesta entrevista la investigadora va interrogar el docent sobre quins eren els objectius que volia aconseguir al final de l'experimentació. -entrevista 2: es va realitzar després de la planificació però abans de començar l'execució de la unitat didàctica a l'aula. En aquesta entrevista la investigadora preguntava al docent sobre les seves impressions abans de començar la implementació. 
-entrevista 3,4 i 5: es van realitzar després de cada sessió de música per conèixer les percepcions del docent després que ell impartís la sessió de música. En aquesta entrevista el docent explicava les seves impressions i reflexions sobre el desenvolupament de la sessió.

-entrevista 6: es va realitzar després d'un any de la conclusió del projecte per contrastar les percepcions.

La taula que es presenta a continuació mostra els temps en què es van realitzar les entrevistes en relació amb les sessions de classe en les que es va implementar la unitat didàctica.

\begin{tabular}{|c|c|c|c|c|c|}
\hline & \begin{tabular}{|l|} 
Dilluns \\
\end{tabular} & Dimarts & Dimecres & Dijous & Divendres \\
\hline $\begin{array}{l}\text { SETMANA } \\
\text { ANTERIOR } \\
\text { INICI UNITAT } \\
\text { DIDÀCTICA }\end{array}$ & Entrevista 1 & & & & \\
\hline $\begin{array}{l}\text { INICI UNITAT } \\
\text { DIDÀCTICA: } \\
\text { Setmana } 1\end{array}$ & Entrevista 2 & & & & $\begin{array}{l}25 \text { maig } 2007 \\
\text { sessió } 1 \\
\text { (música) } \\
\text { Entrevista } 3\end{array}$ \\
\hline Setmana 2 & & & $\begin{array}{l}30 \text { maig } 2007 \\
\text { sessió 2(anglès) }\end{array}$ & $\begin{array}{l}31 \text { maig } 2007 \\
\text { sessió 3(anglès) }\end{array}$ & $\begin{array}{l}1 \text { juny } 2007 \\
\text { sessió } 4 \text { (anglès) } \\
\text { sessió } 5 \\
\text { (música) } \\
\text { Entrevista } 4 \\
\end{array}$ \\
\hline Setmana 3 & & & \begin{tabular}{|l}
6 juny 2007 \\
sessió 6(anglès)
\end{tabular} & $\begin{array}{l}7 \text { juny } 2007 \\
\text { sessió } 7 \text { (anglès) }\end{array}$ & $\begin{array}{l}8 \text { juny } 2007 \\
\text { sessió } 8 \text { (anglès) } \\
\text { sessió } 9 \\
\text { (música) } \\
\text { Entrevista } 5\end{array}$ \\
\hline $\begin{array}{l}\text { UN ANY } \\
\text { DESPRÉS } \\
\text { DEL } \\
\text { PROJECTE }\end{array}$ & Entrevista 6 & & & & \\
\hline
\end{tabular}

Taula 2. Temporització de les entrevistes en relació amb les sessions de classe

Les dades principals es van tractar de la següent manera: les entrevistes van ser enregistrades amb una gravadora digital i el contingut es va transcriure ${ }^{5}$. Per tal de poder realitzar l'anàlisi del contingut s'ha intentat identificar les preocupacions que els participants fan rellevants al llarg de les converses en relació amb les preguntes d’investigació que guien aquest estudi.

Pel que fa a les dades complementàries, de les notes de camp del professor de música, dels diaris dels alumnes, el contingut dels quals ha estat transcrit per facilitar la 
comprensió del manuscrit, i el diari de l’observador, es va procedir a identificar els fragments que poguessin donar suport als continguts que el professor de música destaca al llarg de les entrevistes.

La investigadora que du a terme aquest estudi adopta múltiples rols al llarg de l'experimentació. Per tal de mostrar els diferents rols distingirem dues fases: els rols que adopta en relació al projecte didàctic i els rols que adopta respecte al procés d’investigació.

\begin{tabular}{|l|l|}
\hline \multicolumn{1}{|c|}{ Respecte al projecte didàctic } & \multicolumn{1}{|c|}{ Respecte al procés d'investigació } \\
\hline $\begin{array}{l}\text { Iniciadora: fa la proposta i du a terme el projecte } \\
\text { d'innovació }\end{array}$ & $\begin{array}{l}\text { Observadora participant: observa les sessions de } \\
\text { música i forma part de la plantilla de professorat } \\
\text { del centre }\end{array}$ \\
\hline $\begin{array}{l}\text { Coautora: conjuntament amb el professor de } \\
\text { música planifica i dissenya la unitat didàctica }\end{array}$ & $\begin{array}{l}\text { Coexploradora: reflexiona amb el professor de } \\
\text { música i examina les converses amb aquest docent }\end{array}$ \\
\hline $\begin{array}{l}\text { Coprofessora: responsable d'implementar una part } \\
\text { de la unitat didàctica }\end{array}$ & $\begin{array}{l}\text { Entrevistadora: realitza les entrevistes al professor } \\
\text { de música }\end{array}$ \\
\hline & Analitzadora i presentadora de resultats \\
\hline
\end{tabular}

Taula 3. Rols de la investigadora

\section{Anàlisi}

L’anàlisi consta de dues parts. En primer lloc es farà una reconstrucció narrativa del procés de disseny de la unitat didàctica i, en segon lloc, es procedirà a l'anàlisi de les entrevistes.

El projecte anteriorment mencionat s'inicia en el moment en què la professora d'anglès proposa al professor de música dissenyar una unitat didàctica de música en anglès per implementar en una aula de 3r d'ESO. Tot i que en un principi el professor de música es va mostrar reticent, finalment va acceptar la proposta i va col-laborar en el projecte. Una vegada acceptat el repte, el treball conjunt entre els dos professionals va començar i van començar a prendre les primeres decisions.

La primera decisió era escollir el grup on es duria a terme l'experimentació. La tria es va fer buscant l'hora en què el professor de música tingués classe i la professora d'anglès estigués lliure per poder observar les classes. El grup que reunia aquestes característiques era un grup de tercer d’ESO.

Un cop escollit el grup va sorgir el primer problema: la quantitat d'hores de música, ja que l'àrea de música a tercer d'ESO disposa d' una hora a la setmana durant tot l'any. Es va considerar que la implementació d'un projecte AICLE requeria la màxima exposició a la llengua meta així com el major nombre d’oportunitats per poder 
practicar la llengua interaccionant amb els companys. No obstant, la dedicació d'una hora setmanal de música en el grup escollit no afavoria aquests plantejaments. Així doncs, els dos professionals van decidir dur a terme aquest projecte no només durant les hores de música sinó també durant les hores d'anglès. L’àrea d'anglès a tercer d'ESO disposa de tres hores setmanals durant tot l'any. D’aquesta manera es va acordar que el projecte es duria a terme durant tres setmanes i que estaria repartit entre les hores de música (una hora setmanal) i les hores d'anglès (tres hores setmanals). El conjunt total d'hores dedicades a l'experiència va sumar un total de 9 sessions. Aquesta decisió de sumar les hores de música i les hores d'anglès va suposar també que el professor de música impartiria la unitat didàctica durant les sessions de música i que la professora d'anglès ho faria durant les sessions d'anglès. A més a més, la professora d'anglès estava present durant les sessions de música com a observadora. Així doncs, el problema de la quantitat d'hores quedava resolt amb la suma de dues àrees (música + anglès) que passava a ser una única matèria en la que es realitzava música durant nou hores i en anglès. Suposava també el treball col-laboratiu entre el professor de contingut i la professora de llengua estrangera.

La següent decisió feia referència al tema de la unitat didàctica. El professor de contingut va escollir el tema del Romanticisme, ja que era el següent del programa i va marcar els objectius que volia aconseguir en acabar el projecte.

Una vegada preses les primeres decisions sobre el grup, la temporització, el tema i els objectius, s'inicia el treball collaboratiu entre els dos docents per dissenyar les activitats que formaran part de la unitat didàctica. En aquest punt sorgeix el segon problema: els dos docent partien de visions diferents a l'hora d'enfocar el disseny de la unitat didàctica. Per una banda, una visió centrada en aspectes lingüístics per part de la professora d'anglès, i per una altra banda, una visió centrada en el contingut per part del professor de música. Com a sortida a aquestes dues visions es va negociar l'organització de la unitat didàctica. En aquest moment la professora d'anglès veu necessari conèixer el contingut que el professor de música ensenya a les sessions de música amb els alumnes. A partir d'aquest punt la professora d'anglès es sotmet a un simulacre de classes en les que el professor de música li explica el contingut tal i com ho fa amb els alumnes. Fruit d'aquestes sessions privades entre els dos professionals, denominades internament i també en aquest article “simulacre de classe”, naixerà el producte comú 
que seran les activitats que es dissenyaran per treballar els continguts meta en anglès. Es van dur a terme un total de tres simulacres de classe que permetien planificar setmanalment les sessions de classe tant de música com d'anglès.

Resumint, el procés de presa de decisions pel qual passen els docents per planificar i dissenyar la unitat didàctica segueix l'esquema següent (figura 1):

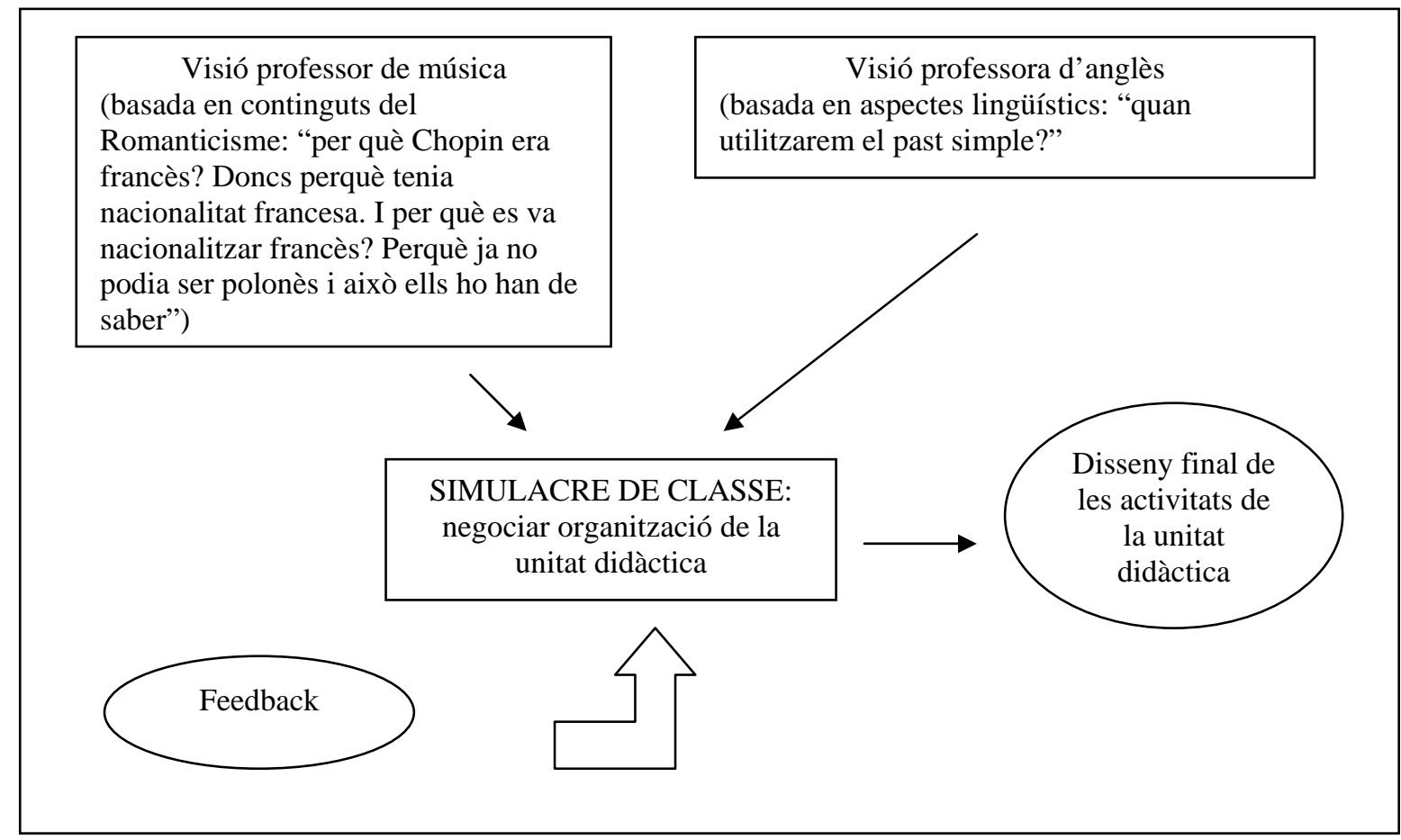

Fig. 1. Procés de presa de decisions

S’ha observat també que la planificació de la unitat didàctica canviava gràcies al feedback que els propis docents anaven trobant mentre implementaven la unitat didàctica i que els servia d'anàlisi per millorar la posterior implementació, així com el feedback que donaven els alumnes en els seus diaris.

A continuació es procedirà a analitzar el contingut de les entrevistes realitzades al docent. Els estadis d'anàlisi que s'han seguit per dur a terme l'anàlisi de les entrevistes són els següents:

a) realitzar un primer anàlisi del contingut de cada entrevista

b) identificar les preocupacions que l'informador fa rellevant a cada entrevista

c) aïllar les seqüències del discurs del docent on les preocupacions apareixen i categoritzar-les. Les categories trobades són les preocupacions que el docent destaca al llarg de les converses i que perfilen l'evolució del seu pensament. 
d) rastrejar els diaris dels alumnes i les notes de camp de la professora quan estiguin disponibles, buscant indicis que corroborin, matisin o qüestionin les percepcions del professor.

e) organitzar de forma diacrònica els temes que el docent destaca al llarg de les entrevistes, de manera que es pugui observar com evoluciona la seva manera de categoritzar els aspectes relacionats amb el fet d'impartir la seva matèria en una llengua estrangera.

Per tal d'assegurar la fiabilitat de les dades s'ha utilitzat una varietat d'informadors (docents, alumnes, observador) i una varietat de dades recollides (entrevistes, diaris) que possibiliten la triangulació metodològica i minimitzen l'error d’observació (Denzin 1970; Escobar 2008b).

Per l'abast d'aquest article no és possible mostrar l'anàlisi del contingut de les sis entrevistes, per tant s'ha optat per, en primer lloc, mostrar la taula on es presenten els temes i subtemes que el docent va destacar al llarg de les converses i, en segon lloc, es procedirà a analitzar l'evolució del pensament del docent respecte a un d'aquests temes.

\begin{tabular}{|l|l|}
\hline \multicolumn{1}{|c|}{ Temes } & \multicolumn{1}{c|}{ Subtemes } \\
\hline \multirow{2}{*}{ 1. Selecció de continguts } & 1.1. Contingut general \\
\cline { 2 - 2 } & 1.2. Biografies \\
\hline 2. Efecte de la llengua estrangera & \\
\hline \multirow{2}{*}{ 3. Enfocament didàctic } & 3.1. Participació \\
\cline { 2 - 2 } & 3.2. Ajustaments pedagògics \\
\cline { 2 - 2 } & 3.3. Classe tradicional vs classe innovadora \\
\hline 4. Comparació entre el grup de control i el grup de & 4.1. Enfocament \\
\cline { 2 - 2 } l'experimentació & 4.2. Resultats \\
\hline 5. Esforç i treball de preparació per part del docent & \\
AICLE & \\
\hline
\end{tabular}

Taula 4. Temes i subtemes del discurs del docent

Un dels temes pel qual el docent va mostrar una constant preocupació al llarg de les entrevistes va ser l'efecte que la llengua estrangera podia tenir en l'apropiació dels continguts curriculars de música per part dels alumnes. A continuació es mostraran fragments del discurs del docent on aquest tema es fa rellevant i es podrà observar com la percepció del professor de música evoluciona al llarg de les sis entrevistes.

A la primera entrevista (després d’acceptar la proposta i abans de començar la planificació) el docent manifesta la seva preocupació per l’efecte que la llengua estrangera pot tenir en els continguts que ell s'ha proposat ensenyar. Observeu: 
Fragment 1

02:35 4 JOS: però ja et dic la biografia tant de:: beethoven com de chopin | a nivell | el més important | el més important sense centrar-me en detalls concrets | que si fos en castellà o en català m'hi centraria | però sent en anglès bua | hi ha moltes coses que són relatives | que no cal vull dir aixòl|

En aquest fragment s'observa com el docent subratlla el fet de tractar els aspectes més importants del tema del Romanticisme sense centrar-se en detalls i manifesta que aquest enfocament és degut al fet que la classe s’imparteixi en anglès.

A la segona entrevista (després de la planificació però abans de la implementació de la unitat didàctica) el professor de música estableix la primera comparació entre el grup de control $^{6}$ (grup b) i el grup de l'experimentació (grup a).

Observeu:

Fragment 2

2 JOS: [...] i clar jo tinc por que veritablement respecte al grup b hi hagi un decalage | és a dir | que els del $b \mid$ tirin | vull dir que arribin on cada any | al seu nivell siguin més bons o més fluixos o com siguin | però que l'a || el fet de que estigui en anglès els mermil| vull dir que| no arribin al mateix punt $\mid$ que el fet que estigui en anglès | faci que no adquireixin els coneixements com si ho haguessin fet en anglès en cast $<0>$

02:31 3 LAU: en català $<0>$

02:32 4 JOS: en català vull dir clar en català || per lo tant vull dir per a mi simplement és | que l'anglès sigui un impediment per ells|| no sé com ho viuran\|

Es pot observar com el docent insisteix en el fet que tem que la llengua estrangera sigui un impediment per tal que el grup de l'experimentació pugui aprendre els continguts del Romanticisme. El professor dóna per suposat que els alumnes del grup de control (grup b) no tindran problemes per comprendre el contingut del Romanticisme, ja que ho fan en català, mentre per al grup de l'experimentació (grup a) el fet que estigui en anglès serà un inconvenient.

A la tercera entrevista (després d’impartir la primera sessió de música) les percepcions del docent respecte a l'efecte de la llengua estrangera comencen a canviar. Observeu:

Fragment 3

04:01 16 JOS: [...] i el que em va cridar l'atenció/ és que es va crear un bon ambient no sé una cosa que anaven sentint anaven | actuant bé dient les coses si preguntava alguna comparació o alguna cosa | i l'anaven dient i estaven atents | jo crec que la qüestió de que estigui en anglès | també fa que hagin d'estar més atents|| clar hi ha la doble vessant | no m'entero de res desconnecto $\backslash$ o | em costa entendre i haig d'estar més atent $\mid$ 
El professor experimenta que el fet que la llengua vehicular sigui la llengua estrangera fa que els alumnes hagin d'estar més atents. Ràpidament reflexiona i diu que hi ha una doble lectura ja que els alumnes davant la dificultat poden desconnectar o posar més atenció. Aquesta percepció del docent queda corroborada amb el comentari següent extret del diari d'un alumne. Observeu:

Fragment 4: Font: diari de l'estudiant B

\section{- Divendres, 25 de maig de 2007 (tarda)}

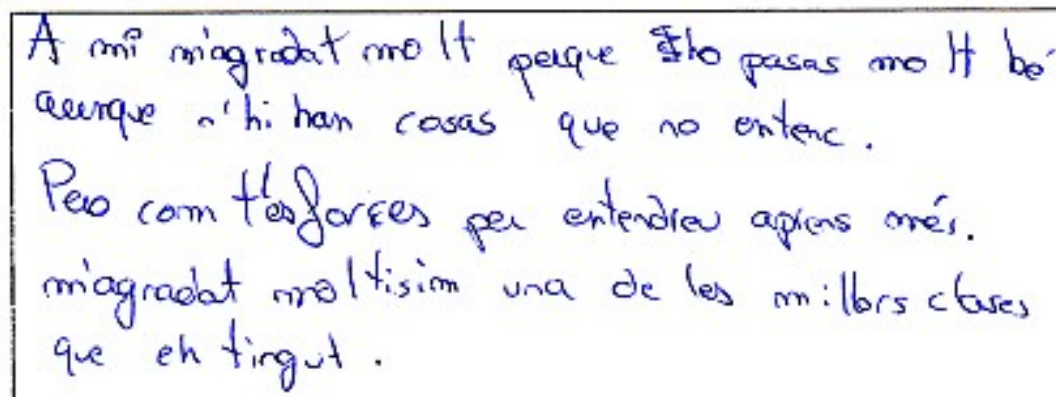

Reformulació:

A mi m’agradat molt perque ho pasas molt bé aunque n’ hi han cosas que no entenc. Pero com t'esforçes per entendreu aprens més. m'agradat moltisim una de les millors clases aue eh tingut.

Aquest alumne valora positivament la sessió de música que van realitzar i apunta que ha d'esforçar-se més per entendre, ja que la llengua vehicular és l'anglès i la comprensió no és immediata. Segons la seva percepció, el fet de realitzar aquest esforç fa que aprengui més.

A la quarta entrevista (després de la segona sessió de música) s’observa com la percepció inicial del docent respecte a l'efecte de la llengua estrangera continua canviant. Observeu:

Fragment 5

09:42 66 JOS: =la susana= no m’he equivocat la susana també diu coses $\bigvee$ i l'ivan $\mid=$ no

09:46 $\quad 67$ LAU: $\quad$ =l'ivan és super tímid= jo també vaig al-lucinar $<0>$

09:48 $\quad 68$ JOS: $\quad$ a classel| ni en català ni en castellà no l'he vist mai no he sentit la seva veu fora de classe |=poques vegades=

09:53 69 LAU: =no diu res=

09:55 $\quad 70$ JOS: $\quad$ i a classe mai $\mid$ deia quatre coses | encara no feia frases $\backslash$ tot i que crec que ell pot fer-nel| deia coses | i | mai no he sentit la seva veul| vull dir la sento | en anglès।| això vol dir que l'anglès algu té | que els hi crida o els fa fer algu que no farien normalment|| perquè ell callaria | agafaria 
tots els apunts i:: \|

En el fragment 5 el professor manifesta sorpresa pel fet que un alumne que mai havia participat a les classes impartides en català, hagi participat a la classe en anglès. El docent apunta que la llengua estrangera motiva la participació dels alumnes, tal i com exemplifica amb el cas d'aquest alumne que fins aquell moment no havia participat.

A la cinquena entrevista (després de la tercera sessió de música) el docent, després d’haver realitzat les tres sessions de música en anglès, reflexiona sobre la seva pràctica docent i manifesta:

Fragment 6

41:18 261 LAU: i que saben els del b que no saben els de l'a/l

41:20 262 JOS: clar saben tota la super biografia que jo a priori és el que els hi demanoV| llavorens | potser això necesita un canvil| m'interessa que sapiguin tot allò/| o no m’interessa amb això ja n’hi ha prou/| però clar això ja és replantejar-me la meva àrea en catalàl| però de moment no me l'estava replantejant|| m'estava replantejant si l'anglès val la pena o no val la penal|

Totes les reflexions que el docent ha experimentat al llarg del projecte han desembocat en aquesta intervenció mostrada en el fragment 6. Al final de la implementació del projecte el professor ha arribat a la conclusió que un canvi en la seva pràctica docent podria ser necessari i això el condueix a replantejar-se la manera com imparteix la seva matèria d'especialització en català. Les reflexions a les quals s’ha sotmès aquest docent durant el desenvolupament de l'experiència AICLE han tingut un efecte directe en la seva pràctica docent a l'aula tradicional.

A la sisena entrevista (un any després de la realització del projecte) el docent recorda l'efecte positiu que va causar la llengua estrangera. Observeu:

Fragment 7

00:10 2 JOS: $\quad$ home l'activitat va estar molt bé | els nanos es van motivar molt | els hi va agradar molt | de fet encara | encara em continuen demanant si continuarem o no i tal/| va estar molt bé/ vull dir | i a més alliçonador per nosaltres fins a cert punt \ ells es van involucrar molt | van utilitzar l'anglès gent que no: que mai no havia parlat a classe per primer cop després de dos anys aconseguia que parlessin i a més en anglès coses rares| bueno | estic content va ser divertit per ells també per mi en moments | estones també vaig veure que van desconnectar | vol dir que tot | de tot s’aprèn | un ja veu | què funcionaria i què ja no funcionaria\|| ells | en quant a aprendre jo penso que van aprendrel| i que amb certes coses els hi va quedar bastant més | que en l'altre grup \=això sí= 
Segons el professor de música, el fet que l'anglès fos la llengua vehicular va fer que l'alumnat hagués d'estar més atent per tal de poder comprendre els continguts. Observeu:

Fragment 8

01:03 4 JOS: però en aquest cas aquests ho van viure com algu nou | una novetat clar | aquest canvi | i el fet que s’haguessin d’esforçar també | perquè clar vull dir no cau així | estic jo parlant en anglès per entendre-ho vol dir que has d'estar més atent | que és clar que ells estiguessin més atents | també ha afavorit que se'n recordessin de més coses | que els hi quedés més | i òbviament | va ser tot molt més visual $\mid$ que una classe normal | jo no porto | no sé quaranta fotos | i un munt de fitxes | i no ens en anem a internet | i tot això fa | que la classe fossin més dinàmiques del normal | i molt visuals | molt molt molt visuals i a més amb esquemes i tot | i això fa que la classe se’ls hi quedés només pel fet de veure una imatge | se’ls hi quedés més\| això síl||

A més a més, el professor apunta que va haver de realitzar ajustaments pedagògics per abordar els continguts, cosa que no fa a la classe tradicional en català. Aquest fet posa en evidència que la llengua estrangera és un filtre entre professor i alumnes que fa que el professor hagi de dotar-se de material de suport per facilitar la comprensió, ja que la comprensió en anglès a l'aula AICLE no és immediata, al contrari del que passa a l'aula tradicional en llengua primera.

A continuació es presenta una taula que mostra la categorització que fa el docent del tema de l'efecte de la llengua estrangera i que és fruit de l'anàlisi realitzat prèviament del discurs del docent. Els exemples del discurs del docent on apareixen aquestes categories es presenten en cursiva i el torn d’on han estat extretes entre parèntesi. L’objectiu d'aquesta taula és mostrar l'evolució del pensament del docent respecte a aquest tema des de l'inici fins al final del projecte. Observeu:

2. Efecte de la llengua estrangera

\begin{tabular}{|l|l|}
\hline Entrevista 1 & $\begin{array}{l}\text { Hipòtesi inicial - valoració negativa: ús de LE impossibilita centrar-se en detalls } \\
\text { que si fos en català o castellà m'hi centraria però sent en anglès hi ha moltes coses } \\
\text { que són relatives (torn 4) }\end{array}$ \\
\hline Entrevista 2 & $\begin{array}{l}\text { Hipòtesi inicial - valoració negativa: ús de LE impossibilita apropiar-se de } \\
\text { continguts meta } \\
\text { que el fet que estigui en anglès faci que no adquireixin els coneixements com si ho } \\
\text { haguessin fet en català (torn 2) }\end{array}$ \\
\hline
\end{tabular}




\begin{tabular}{|l|l|}
\hline Entrevista 3 & $\begin{array}{c}\text { que l'anglès sigui un impediment per ells (torn 4) } \\
\text { Replantejament hipòtesi inicial - valoració positiva: ús de LE requereix més atenció } \\
\text { per part de l'alumnat } \\
\text { jo crec que el fet que estigui en anglès també fa que hagin d'estar més atents } \\
\text { (torn 16) }\end{array}$ \\
\hline Entrevista 4 & $\begin{array}{l}\text { Replantejament hipòtesi inicial - valoració positiva: ús de LE motiva que l' alumnat } \\
\text { participi } \\
\text { això vol dir que l'anglès algu té que els hi crida o els fa fer algu que no farien } \\
\text { normalment (torn 16) }\end{array}$ \\
\hline Entrevista 5 & $\begin{array}{c}\text { Constatació: ús de LE ha afavorit l'aprenentatge } \\
\text { estic jo parlant en anglès per entendre-ho vol dir que has d'estar més atent que és } \\
\text { clar que ells estiguessin més atents també ha afavorit que se'n recordessin de més } \\
\text { coses (torn 4) }\end{array}$ \\
\hline
\end{tabular}

Taula 5. Tema 2: Efecte de la llengua estrangera

\section{Conclusions}

En primer lloc es fa patent la importància d’investigar integrant diferents punts de vista - el dels docents i el dels alumnes -, però també el del professor de música i la professora d'anglès. S’ha descrit el procés de planificació i implementació de la unitat didàctica que es va dur a terme gràcies al treball col-laboratiu entre el professor de música i la professora d'anglès. Els docents partien de visions diferents i van treballar conjuntament en la planificació i implementació de la unitat didàctica amb l’objectiu d'obtenir un producte comú. Durant aquest procés els docents van sentir la necessitat de negociar per aconseguir aquest objectiu.

En segon lloc s’observa una evolució del pensament del professor de contingut des de la primera entrevista abans de començar l'experimentació fins al final del projecte. En realitzar una experiència innovadora d'aquest tipus el docent té l'oportunitat de contrastar les seves idees preconcebudes amb la realitat que va experimentant. Les converses entre investigador i informador l'ajuden a qüestionar-se vells plantejaments i fa que adopti una posició dinàmica, disposat a introduir innovacions en la seva forma habitual d'ensenyar. L’evolució que mostra el professor en la forma de categoritzar la realitat té una repercussió immediata en l'activitat docent que realitza a l'aula experimental. Pel que fa a la llengua estrangera com a llengua 
vehicular, abans de començar l'experimentació el docent creu que l'anglès serà un inconvenient per tal que els alumnes puguin apropiar-se dels continguts meta. No obstant, al principi de l'experiència, després de la primera sessió de música en anglès, el docent percep que el fet que la llengua vehicular sigui la llengua estrangera fa que els alumnes tinguin una actitud receptiva i atenta vers l'aprenentatge. Aquesta constatació desencadena un procés de reformulació dels seus plantejaments.

Finalment, les converses entre investigador i informador han situat el docent en un espai de reflexió sobre la seva pràctica docent. A través de l'experiència AICLE el docent s'ha qüestionat com dur a terme la seva matèria d'especialització en llengua primera. La visió constructivista i interaccionista de l'aprenentatge que el docent aplica amb el grup de l'experimentació trenca amb la visió tradicional sobre l'aprenentatge que aplica amb el grup de control. El fet que el docent abordi la docència de la seva matèria d'especialització des de perspectives teòrico-pràctiques sobre l'aprenentatge tan distants desencadena un procés de reflexió sobre les formes d'ensenyar i d'aprendre. S’observa clarament una preferència per la dinàmica de classe desencadenada amb el grup de l'experimentació, tanmateix aquesta reflexió no el condueix a modificar la seva pràctica docent amb el grup de control.

Aquesta experiència evidencia el canvi de pràctica docent que els professors han d'experimentar i canviar cap a una docència centrada en l'alumne. Tal i com el professor de música d'aquest estudi va afirmar, és més còmode per al docent seguir amb el format de "classe magistral i guix” però aquest format no és compatible amb la bona pràctica d'un programa AICLE. Segons Escobar (2001):

la puesta en práctica de programas AICLE es un reto para los centros educativos por el cambio de mentalidad que suponen en el profesorado y la administración educativa, y la reorganización de tiempos y recursos humanos que requieren, pero es un vía que se abre con fuerza en un mundo cada vez más multicultural y multilingüístico. (p.230)

Aquest estudi ha pretès interpretar l'evolució del pensament del professor de música que es va brindar a participar en un projecte d'innovació que al final va canviar el seu enfocament. S'ha fet evident que una petita experiència d'innovació educativa pot arribar a tenir un gran potencial de càrrega innovadora important, fet que queda corroborat amb la voluntat de seguir treballant en aquesta línia d’innovació educativa per part del professor de contingut després de l'experimentació i les posteriors 
reflexions. Igualment, els resultats d'aquesta experiència han tingut un efecte positiu en la formació de la investigadora com a docent, ja que ha gaudit d'un enriquiment tant de continguts com de recursos pedagògics d'una altra matèria d'especialització, en aquest cas de la música.

\section{Referències bibliogràfiques}

Allwright, D. i Bailey, K.M. (1991) Focus on the Language Classroom. An introduction to classroom research for language teachers. Cambridge: CUP.

Ballesteros, C., Llobera, M., Cambra, M., Palou, J., Riera, M., Civera, I. i Perera, J. (2001) El pensamiento del profesor. Enseñanza de lengua y Reforma. Dins de: Camps, A. (coord.) El aula como espacio de investigación y reflexión, pp. 195207. Barcelona: Graó.

Burgess, R. (1982) The Unstructured Interview as a Conversation. Dins de: Burgess, R. (ed.) Field Research: a Sourcebook and Field Manual, pp. 107-110. London: Allen and Unwin.

Cambra, M. (2000) El pensament del professor: formació per a la pràctica reflexiva. Dins de: Camps, A., Ríos, I. i Cambra, M. (coord.) Recerca i fomació en didàctica de la llengua, pp. 161-172. Barcelona: Graó.

Clark, C.M. i Peterson, P.L. (1986) Procesos de pensamiento de los docentes. Dins de: Wittrock, M.C. La investigación en la enseñanza, III Profesores y alumnos, pp. 444-539. Barcelona: Paidós.

Cohen, L. i Manion, L. (1985) Research Methods in Education. London: Croom Helm.

Coll, C. (2002) Constructivismo e intervención educativa ¿Cómo enseñar lo que ha de construirse? Dins de: Barberà, E. et al. El constructivistmo en la práctica, pp. 11-32. Barcelona: Graó.

Corredera, A. (2008) Uso de la lengua extranjera en tareas para aprender ciencias en inglés: ¿hablan en inglés? Dins de: Monroy, R., Sánchez, A. (eds) 25 Años de Lingüística Aplicada en España: Hitos y Retos / 25 Years of Applied Linguistics in Spain: Milestones and Challenges, pp. 295-307. Murcia: Servicio de Publicaciones de la Universidad de Murcia.

Coyle, D. (2006) Developing CLIL: Towards a Theory of Practice. Dins de: APAC Monograph, 6: 5-29. Barcelona: APAC.

Denzin, N.K. (ed.) (1970) Sociological Methods: a Source Book. Chicago: Aldine.

Escobar, C. (2001) La organización de la enseñanza. Dins de: Bernaus, M., Nussbaum, L. (eds.) Didáctica de las lenguas extranjeras en la Educación Secundaria Obligatoria, pp. 207-232. Madrid: Síntesis Educación.

Escobar, C., Sánchez, A. (2007) Mejoras en la fluidez y repertorio léxico en aulas AICLE inclusivas de ciencias naturales en inglés en Cataluña. Comunicació presentada en el $X X V$ Congreso Internacional de AESLA. Universidad de Murcia. Murcia: 19-21 abril, 2007.

Escobar, C. (2008a) Talking English to learn Science. A CLIL experience in Barcelona. Dins de: Dooly, M. i D. Eastment (eds.) How we're going about it. 'Teachers' vioces on innovative approaches to teaching and learning languages', pp. 154169. Cambridge: Cambridge Scholar Press. 
--- (2008b) Memoria científica del projecte 2006ARIE10011: Formular un model de formació professionalitzador adreçada al professorat d'aules de semiimmersiió (FOPP-SI). AGAUR. Disponible a:

http://www.recercat.cat/bitstream/2072/14403/1/Cristina_Escobar.pdf

Escobar, C. i Sánchez, A. (2009) Language Learning through Tasks in a CLIL Science Classroom. A: Porta Linguarum, 11: 65-83.

Evnitskaya, N. i Aceros, J.C. (2008) We are a good team: el contrato didáctico en parejas de aprendices de lengua extranjera. Revista Española de Lingüística Aplicada, 21: 45-70.

Horrillo-Godino, Z. (2008a) Two Teachers in the Classroom: Teaching Maths in English. Comunicació presentada a Global English. Local Perspectives. 31st Annual Convention TESOL-SPAIN. Universidad Europea de Madrid, 9 marzo 2008.

--- (2008b) Initial Steps in the co-construction of a space of dialogue between an expert in foreign language pedagogy and an expert in social science pedagody. A case study. Tesis de Màster, Departament de Didàctica de la Llengua, la Literatura i les Ciències Socials, Universitat Autònoma de Barcelona. Sense publicar.

Hsieh, H-F. i Shannon, S. (2005) Three Approaches to Qualitative Content Analysis. A: Qualitative Health Research, 15: 1277-1288.

Mondada, L.,i Pekarek, S. (2004) Second Language Acquisition as Situated Practice: Task Accomplishment in the French Language Classroom. The Modern Language Journal, 88, 4: 501-518.

Pallarès, O. i Petit, C. (2008) 1+1=1. Una nova aritmètica pedagògica. Comunicació presentada a: II Trobada de semiimmersió a Catalunya: la col·laboració entre dos experts a l'aula SI. Organitzada per grup GREIP/CLIL-SI, ICE-UAB i Facultat de Ciències de l'Educació Universitat Autònoma de Barcelona.

Roquet, M. i Escobar, C. (2004) Is it possible to teach history in English to students with a limited command of the language? EuroClic Newsletter, pp. 1-17.

Schön, D. (1998) El profesional reflexivo: cómo piensan los profesionales cuando actúan. Barcelona: Paidos.

Silverman, D. (1993) Interpreting Qualitative Data: Methods for Analysing Talk, Text and Interaction. London: Sage.

Referència dels autors:

Anna Corredera Capdevila és llicenciada en Filologia Anglesa (UAB, 2000) i té un Màster de recerca en Didàctica de la Llengua i de la Literatura (UAB, 2009). És professora de llengua anglesa a l'Escola Túrbula de Sant Adrià de Besòs des de 2001 i des de 2007 du a terme, conjuntament amb altres professors d'aquest centre, experiències en el camp de l'aprenentatge integrat de continguts i llengua tant a l'ESO com al Batxillerat. Té articles publicats d'aquestes experiències i ha presentat comunicacions en diverses trobades sobre semiimmersió. Els seus àmbits d’interès en recerca són l'aprenentatge integrat de continguts i llengua, la música i la literatura.

Email (autora principal): anna.corredera@terra.es

Bruno J. Ruiz Lorenzo és llicenciat en Pedagogia Musical pel Conservatori Superior de Música del Liceu (2000-2001). Ha fet classes a diferents escoles de música i a l’ESO des del 2001 i és professor de l'Escola Túrbula de Sant Adrià de Besòs des de 2005. Té experiència en projectes AICLE des de 2007 i ha presentat comunicacions en diverses trobades sobre semiimmersió. 
1 Les sigles AICLE signifiquen Aprenentatge integrat de contingut i llengua i amb aquestes sigles es designen els programes que integren l'aprenentatge d'una àrea curricular a través d'una llengua estrangera, en el marc d'aquest estudi. El seu equivalent en anglès és CLIL (Content and language integrated learning).

2 S'entén com a professor de contingut el docent que imparteix matèries curriculars no lingüístiques. En el marc d'aquest estudi el professor de contingut és un professor de música.

3 Aquest estudi va ser defensat com a Treball de Recerca del Màster de Recerca en Didàctica de la Llengua i la Literatura de la Facultat de Ciències de l'Educació de la Universitat Autònoma de Barcelona el juliol de 2009. El present estudi s'ha dut a terme en el marc dels projectes col-laboratius 2006ARIE100011 i 2007ARIE00011 "Disseny i experimentació d'un model de formació del professorat per a aules de semiimmersió en llengua estrangera”, finançats per l'AGAUR (Generalitat de Catalunya). 4 Voldríem donar les gràcies a la Direcció del centre, als alumnes de 3r d'ESO i als nostres companys que sempre es van mostrar receptius i disposats a ajudar-nos.

5 Les convencions de transcripció utilitzades en aquest treball segueixen la codificació proposada pel grup GREIP (Grup de Recerca en Ensenyament i Interacció Plurilingües) de la Universitat Autònoma de Barcelona i són les següents:

seqüències tonals terminals: descendent $\backslash$; ascendent /

pauses: pausa breu | ; pausa mitjana $\|$; sense pausa $<0>$

prolongació del so final :

solapament =text parlant $\mathrm{A}=$

$=$ text parlant $\mathrm{B}=$

Les abreviatures utilitzades corresponen als noms dels participants a les entrevistes: JOS: (José) és el professor de música i LAU: (Laura) és la investigadora.

6 El grup a fa referència al grup de l'experimentació que es troba en un context AICLE fent la classe de música en anglès. El grup b fa referència al grup de control que està aprenent el mateix contingut però en llengua primera, en aquest cas català. 